\title{
Bactérias promotoras do crescimento radicular em plântulas de dois cultivares de arroz irrigado por inundação
}

\author{
Israel Mendes Sousa ${ }^{1}$, Adriano Stephan Nascente ${ }^{2}$, Marta Cristina Corsi de Filippi ${ }^{2}$ \\ ${ }^{1}$ Universidade Federal de Goiás - UFG. ${ }^{2}$ Embrapa Arroz e Feijão, Brasíli, DF. E-mail: israelmmendes128@gmail.com
}

\begin{abstract}
Resumo
Para o crescimento e desenvolvimento na natureza, as plantas contam com os benefícios de microrganismos residentes em sua rizosfera. Rizobactérias promotoras de crescimento vegetal (RPCV) são exemplos desses microrganismos que interagem de forma benéfica com espécies vegetais. Portanto, a inoculação de sementes com RPCV pode representar uma alternativa importante e sustentável para melhorar o desenvolvimento inicial e a produção de plantas cultivadas. Objetivou-se com esse estudo determinar o efeito da microbiolização de sementes com RPCV no comprimento radicular de plântulas de arroz irrigado por inundação. Em condições controladas, conduziram-se dois experimentos com cultivares de arroz irrigado (BRS Catiana e BRS A702 CL), em delineamento inteiramente casualizado, com sete tratamentos e 10 repetições. Os tratamentos constituíram-se de seis microrganismos: BRM32109 (Bacillus sp.), BRM32110 (Bacillus sp.), BRM32111 (Pseudomonas fluorescens), BRM32112 (Pseudomonas sp.), BRM32113 (Burkholderia pyrrocinia), BRM32114 (Serratia sp.) e um controle (sem microrganismo). Os maiores comprimentos radiculares foram apresentados pelas sementes tratadas com os isolados BRM32110, BRM32112, BRM32109 e BRM32114. Para ambas cultivares houve significância quando comparado microrganismos e controle. Destaque para as sementes da cultivar BRS Catiana, que quando tratadas com os isolados BRM32110 e BRM32112 apresentaram aumento médio de $25,7 \%$ no comprimento radicular, em comparação com o tratamento controle. Para a cultivar BRS A702 CL, todos os microrganismos proporcionaram incrementos com um valor médio de $31 \%$ no comprimento radicular das plântulas de arroz. Com base nos resultados pode-se inferir que as RPCV proporcionam incrementos significativos no comprimento radicular de plântulas de cultivares de arroz irrigado por inundação.

Palavras-chave: bioagentes; desenvolvimento sustentável; microrganismos indutores de crescimento; Oryza sativa.

\section{GROWTH PROMOTING BACTERIA ON ROOT LENGTH OF SEEDLINGS OF TWO FLOODED LOWLAND RICE CULTIVARS}

\section{Abstract}

For growing and development in nature, plants count with the benefits of microorganisms residing in their rhizosphere. Plant growth promoting rhizobacteria (PGPR) are some of these microorganisms that interact in a beneficial way with plant species. Therefore, seed inoculation with PGPR can be an important and sustainable alternative to improve initial development and crop production. The aim was to determine effect of seeds microbiolization with PGPR on root length of flooded lowland rice seedlings. Under controlled conditions, two experiments were conducted with lowland rice cultivars (BRS Catiana and BRS $A 702 \mathrm{CL}$ ) in completely randomized design, with seven treatments and 10 replications. The treatments consisted of six microorganisms: BRM32109 (Bacillus sp.), BRM32110 (Bacillus sp.), BRM32111 (Pseudomonas fluorescens), BRM32112 (Pseudomonas sp.), BRM32113 (Burkholderia pyrrocinia), BRM32114 (Serratia sp.) and a control (no microorganism). Only the cultivar BRS Catiana showed difference among the treatments. The highest root length was presented by the seeds treated with the isolates BRM32110, BRM32112, BRM32109, and BRM32114. Both of cultivars had significance when compared microorganisms to the control. Highlight for seeds of cultivar BRS Catiana, that when treated with the isolates BRM32110 and BRM32112 presented an average increase of $25.7 \%$ on the root length, compared 
to control treatment. For the cultivar BRS A702 CL, all the microorganisms provided increments with average value of $31 \%$ in the root length of rice seedlings. Based on the results it can be inferred that PGPR provide significant increases in seedling root length of flooded lowland rice cultivars.

Keywords: bioagents; sustainable development; growth inducing microorganisms; Oryza sativa.

\section{Introdução}

O arroz (Oryza sativa L.) é considerado a base alimentar de metade da população mundial (IRRI, 2010). Por ser uma fonte rica em carboidratos, é caracterizado como importante fonte de energia para o metabolismo humano, além disso, é também fonte de proteínas, sais minerais e vitaminas do complexo B (NAVES; BASSINELO, 2006).

A área total plantada com arroz no Brasil é de aproximadamente 1,97 milhão de hectares, com produção de 12 milhões de toneladas. $O$ arroz irrigado por inundação é plantado principalmente nos estados do Rio Grande do Sul, Santa Catarina e Tocantins. A área cultivada nesse sistema representa $72,6 \%$ do total de área plantada com arroz e, $89 \%$ da produção nacional, apresentando rendimento médio de $7.513 \mathrm{~kg} \mathrm{ha}^{-1}$ (CONAB, 2018).

O uso de bioagentes constitui uma opção sustentável para aumentar a produção de culturas como o arroz. Espécies de rizobactérias promotoras de crescimento vegetal (RPCV) têm sido relatadas na literatura promovendo o crescimento e desenvolvimento vegetal por meio da sinalização química que intensificam o metabolismo: das vias de hormônios vegetais, como auxinas, citocininas e giberelinas (AHEMAD; KILBRET, 2014); de enzimas relacionadas ao estresse oxidativo (RAJ et al., 2012) e com as alterações estruturais e bioquímicas nas células das plantas, induzindo, assim, a resistência sistêmica de plantas (FILIPPI et al., 2011) e; de absorção de macronutrientes como $\mathrm{N}$ e $\mathrm{P}$, melhorando características fisiológicas como aumento em taxas fotossintéticas (NASCENTE et al., 2017a).

Existem resultados promissores de microrganismos coletados da rizosfera de arroz de terras altas proporcionando incrementos significativos no desenvolvimento das plantas (FILIPPI et al., 2011; NASCENTE et al., 2017a). No entanto, esses microrganismos podem também ser promissores para as cultivares de arroz irrigado (MENDES et al., 2017). Corroborando essa informação, estudo realizado em casa de vegetação mostrou que esses microrganismos, coletados da rizosfera do arroz de terras altas, interagiram positivamente na promoção de crescimento de arroz irrigado cultivar BRS Catiana (NASCENTE et al., 2017b).

Entretanto, ainda são poucos os resultados que explicam como estes microrganismos interagem com as plantas e quais os mecanismos envolvidos na promoção do crescimento. Portanto, tornam-se necessários mais estudos para aprofundar os conhecimentos dos efeitos benéficos proporcionados pelas RPCV em cultivares, dentro de uma mesma espécie vegetal. Por exemplo, Oliveira et al. (2003) relatam que as RPCV podem produzir hormônios vegetais que causam melhoria na estrutura radicular das plantas. Assim, o maior desenvolvimento radicular pela inoculação com RPCV pode implicar em vários efeitos como proporcionar incrementos na absorção da água e minerais, maior tolerância a estresses como salinidade e seca, resultando em planta mais vigorosa e produtiva (HUNGRIA, 2011).

O presente trabalho teve a hipótese de que a microbiolização de sementes de arroz irrigado com microrganismos benéficos, selecionados da rizosfera do arroz de terras altas (FILLIPI et al., 2011; MARTINS, 2015), irá proporcionar maior desenvolvimento radicular em comparação com sementes não tratadas. Por isso, com esse estudo se objetivou determinar o efeito de rizobactérias no comprimento radicular de cultivares (BRS Catiana e BRS A702 CL) de arroz irrigado por inundação no ambiente tropical.

\section{Material e Métodos}

Os experimentos foram conduzidos no laboratório de Microbiologia Agrícola, sede da Embrapa Arroz e Feijão, município de Santo Antônio de Goiás, em agosto de 2018. O delineamento experimental foi inteiramente casualizado, com sete tratamentos e 10 repetições. Os tratamentos constituíram-se de seis microrganismos: BRM32109 (Bacillus sp.), $\begin{array}{llll}\text { BRM32110 (Bacillus } & \text { sp.), } & \text { BRM32111 }\end{array}$ 
(Pseudomonas fluorescens), BRM32112 (Pseudomonas sp.), BRM32113 (Burkholderia pyrrocinia), BRM32114 (Serratia sp.) e um controle (sem microrganismo). Os isolados de rizobactérias promotoras de crescimento vegetal (RPCV) são partes integrantes da coleção de
Microrganismos Multifuncionais da Embrapa Arroz e Feijão. Características bioquímicas e classificação taxonômica dos microrganismos utilizados estão descritas na Tabela 1.

Tabela 1. Código da coleção, origem, características bioquímicas e classificação taxonômica dos seis isolados de rizobactérias utilizadas para microbiolização de sementes de arroz irrigado cultivares BRS Catiana e BRS A702 CL.

\begin{tabular}{|c|c|c|c|c|c|c|c|c|}
\hline \multirow[t]{2}{*}{ Código $^{a}$} & \multirow[t]{2}{*}{ Origem $^{b}$} & \multirow[t]{2}{*}{ Cor $^{c}$} & \multicolumn{5}{|c|}{ Bioquímica $^{c}$} & \multirow[t]{2}{*}{ Taxonomia $^{c}$} \\
\hline & & & $\mathrm{AlA}^{\mathrm{d}}$ & $\mathrm{Cel}^{\mathrm{e}}$ & Fosf $^{f}$ & Sider $^{g}$ & Biof $^{h}$ & \\
\hline BRM32109 & GO/Brasil & Branca & & + & + & & + & Bacillus sp. \\
\hline BRM32110 & PA/Brasil & Branca & & + & + & + & + & Bacillus sp. \\
\hline BRM32111 & PA/Brasil & Amarela & & + & + & + & + & Pseudomonas fluorescens \\
\hline BRM32112 & GO/Brasil & Amarela & & + & + & + & + & Pseudomonas sp. \\
\hline BRM32113 & PA/Brasil & Rosa & + & + & & + & + & Burkholderia pyrrocinia \\
\hline BRM32114 & PA/Brasil & Rosa & + & + & + & + & + & Serratia sp. \\
\hline
\end{tabular}

${ }^{\mathrm{a}}$ Número do código dos isolados de rizobactérias pertencentes à coleção de microrganismos multifuncionais da Embrapa Arroz e Feijão;

brigem geográfica de cada isolado;

${ }^{\text {c} C o r ~ d a ~ c o l o ̂ n i a, ~ c a r a c t e r i ́ s t i c a ~ b i o q u i ́ m i c a ~ e ~ c l a s s i f i c a c ̧ a ̃ o ~ t a x o n o ̂ m i c a ~ d e ~ c a d a ~ i s o l a d o ~ d e s c r i t o ~ p o r ~ M a r t i n s ~(2015) ; ~}$

dprodução de ácido indolacético;

eProdução de celulase;

fProdução de fosfatase;

${ }^{g}$ Produção de sideróforos, metodologia descrita por Martins (2015);

hactéria que produz biofilme.

A partir de culturas com crescimento em meio sólido (ágar nutriente), suspensões com os microrganismos foram preparadas em meio líquido 523 (caldo nutriente) (KADO; HESKETT, 1970), em incubadora agitadora, por 24 horas a $28{ }^{\circ} \mathrm{C}$. A concentração da suspensão de cada microrganismo foi ajustada em espectrofotômetro a uma absorbância de 0,7 , em comprimento de onda de $540 \mathrm{~nm}$, correspondendo a $1 \times 10^{8}$ unidades formadoras de colônia (UFC) por $\mathrm{mL}$. As sementes de cada genótipo de arroz foram desinfestadas com álcool $70 \%$ por um minuto e hipoclorito de sódio por um minuto, lavadas com água destilada, e secas a temperatura ambiente (ao redor de 28 ${ }^{\circ} \mathrm{C}$ ). As sementes foram imersas nas suspensões de células de cada bactéria para a microbiolização, e o controle imerso em água, durante 24 horas a temperatura de $25{ }^{\circ} \mathrm{C}$, sob agitação constante, de acordo com metodologia proposta por Filippi et al. (2011).

Antes da realização da semeadura foi feito o teste de vigor e germinação das sementes utilizando metodologia recomenda por BRASIL (2009). Verificou-se que sementes da cultivar BRS A702 CL apresentaram taxa de vigor de $37,25 \%$ e germinação de $67,7 \%$, as sementes de BRS Catiana apresentaram taxa de vigor de 97,5\% e germinação de $99 \%$. As sementes de arroz foram semeadas em tubos de ensaio contendo $15 \mathrm{~mL}$ de ágar-água $(0,8 \% \mathrm{~m} / \mathrm{v})$. Os tubos foram colocados em câmara de germinação a $28{ }^{\circ} \mathrm{C}$, com fotoperíodo de 12 horas e, o comprimento radicular das plântulas foi medido com régua graduada, antes que começasse a se desenvolver as raízes fasciculadas, aos 10 dias após a semeadura, seguindo metodologia proposta por Sperandio et al. (2017). Cada tubo de ensaio continha uma semente e constituiu uma unidade experimental.

Os dados foram submetidos à análise de variância. As médias entre os tratamentos de RPCV foram comparadas pelo teste LSD $(p \leq 0,05)$ e, os tratamentos com microrganismos foram comparados individualmente com o controle pelo teste de Dunnett $(p \leq 0,05)$, analisados no pacote estatístico SAS (SAS, 1999).

\section{Resultados e Discussão}

O comprimento radicular das plântulas de arroz da cultivar BRS Catiana diferiu $(p \leq 0,05)$ entre os tratamentos (Tabela 2). Por outro lado, 
não houve diferença entre os tratamentos com RPCV para a cultivar BRS A702 CL, pelo teste LSD. Além disso, sementes de arroz microbiolizadas com as rizobactérias proporcionaram comprimentos radiculares superiores das plântulas de arroz em ambas as cultivares, em comparação com as plântulas de arroz do tratamento controle.

Para a cultivar BRS Catiana, os maiores comprimentos radiculares foram proporcionados pelas sementes de arroz tratadas com o isolado BRM32110 (Bacillus sp.) que diferiu significativamente dos isolados BRM32111 e BRM32113 (Tabela 2). Adicionalmente, as sementes tratadas com os isolados BRM32110 e BRM32112 proporcionaram crescimento radicular de 8,9 e 8,7 centímetros respectivamente, aos 10 dias após a semeadura, diferindo das sementes do tratamento controle que demonstraram crescimento radicular de 7,0 $\mathrm{cm}$. Os isolados BRM32110 e BRM 32112 proporcionaram aumento médio de 24,3 e $27,1 \%$, respectivamente, no comprimento radicular das plântulas em comparação com tratamento controle.

Com relação a cultivar BRS A702 CL, em média, a microbiolização com os diferentes isolados bacterianos aumentou em $31 \% \quad 0$ comprimento radicular das plântulas de arroz em comparação com o controle (Tabela 2). Esses resultados diferentes do efeito das RPCV nas duas cultivares de arroz irrigado por inundação, estudadas no presente experimento (BRS Catiana e BRS A702 CL) comprova as informações de Mendes et al. (2017), que fez uma revisão dos efeitos das rizobactérias nas culturas agrícolas, e relataram que as RPCV atuam de maneira diferenciada em cultivares dentro da mesma espécie vegetal. De acordo com os autores, o solo é a principal fonte de espécies microbianas colonizando a rizosfera, e o genótipo da planta impulsiona, em parte, a seleção dos microrganismos depositando exsudatos específicos na interface solo-raiz. Assim, as espécies de plantas, cultivares e tipo de solo são os principais impulsionadores da composição e funcionamento do microbioma da rizosfera. Nesse sentido, BRS Catiana e BRS A702 CL devem ter liberado diferentes exsudados durante o processo de germinação, o que proporcionou melhor ambiente para o desenvolvimento de microrganismos distintos e por conseguinte, causando efeitos diferenciados em cada genótipo de arroz avaliado. Estudos são necessários para verificar o efeito bioquímico e fisiológico causado por essas RPCV e identificar exatamente aonde elas causaram alterações na planta que resultou no maior comprimento radicular por diferentes agentes em cada cultivar.

Tabela 2. Comprimento radicular de plântulas de arroz irrigado tropical cultivares BRS Catiana e BRS A702 $\mathrm{CL}$, com sementes microbiolizadas com seis isolados de rizobactérias promotoras de crescimento vegetal.

\begin{tabular}{ccc} 
& \multicolumn{2}{c}{ Comprimento radicular $(\mathrm{cm})$} \\
\hline Rizobactérias & BRS Catiana & $\mathrm{A} \mathrm{702 \textrm {CL }}$ \\
BRM32110 & $8,9 \mathrm{a}^{*}$ & $6,3 \mathrm{a}^{*}$ \\
BRM32112 & $8,7 \mathrm{ab} *$ & $5,3 \mathrm{a}^{*}$ \\
BRM32109 & $8,4 \mathrm{abc}$ & $6,0 \mathrm{a}^{*}$ \\
BRM32114 & $8,2 \mathrm{abc}$ & $6,0 \mathrm{a}^{*}$ \\
BRM32111 & $8,1 \mathrm{bc}$ & $7,0 \mathrm{a}^{*}$ \\
BRM32113 & $7,8 \mathrm{c}$ & $5,6 \mathrm{a}^{*}$ \\
\hline Controle & 7,0 & 4,6 \\
\hline FV & ANOVA (Probabilidade do teste $\mathrm{F})$ \\
Rizobactéria & 0,041 & 0,022 \\
\hline CV (\%) & 11,77 & 22,06 \\
\hline
\end{tabular}

Médias seguidas pela mesma letra, dentro de cada cultivar, não diferem entre si pelo teste LSD. Comparações entre microrganismos e controle, significativas pelo teste de Dunnett ao nível de significância $5 \%$ indicadas por *.

Com base em resultados prévios de vigor e germinação, testados conforme recomenda Brasil (2009), verificou-se que sementes da cultivar BRS A702 CL apresentaram baixa taxa de vigor $(37,25 \%)$ e germinação $(67,7 \%)$, mas, a microbiolização das sementes com as RPCV proporcionou um "arranque inicial" das plântulas, uma vez que proporcionou incrementos significativos no comprimento radicular quando comparado com o tratamento controle (Tabela 2). Esses resultados demonstram o potencial de uso dessa tecnologia para 
proporcionar desenvolvimento mais rápido e promover maior incremento no comprimento radicular das plântulas, mesmo com menor taxa de vigor e germinação.

Sperandio et al. (2017) compararam os isolados BRM32110 e BRM32114 com tratamento sem microrganismo em genótipo de arroz de terras altas (BRS Primavera) e concluíram que as sementes tratadas com RPCV proporcionaram aumento do comprimento radicular, corroborando com os resultados deste estudo, além de proporcionarem maior quantidade de biomassa de raiz e folha nas plantas avaliadas aos 24 dias após a emergência. Rêgo et al. (2014) caracterizaram mudanças anatômicas e bioquímicas em raízes de plantas de arroz de terras altas tratadas com os microrganismos BRM32111 e BRM32113, que podem ajudar a esclarecer as possíveis causas dos nossos resultados. Eles concluíram que ambos isolados promoveram modificações na arquitetura das raízes, como, aumento em comprimento e diâmetro radicular, expansão do córtex e dos espaços de aerênquimas.

Os resultados proporcionados no presente estudo podem ser explicados, em parte, pela característica apresentada por alguns dos isolados, BRM32113 e BRM32114, como a produção de ácido idolacético (AIA) (Tabela 1; MARTINS, 2015). O AIA é um hormônio vegetal regulador de crescimento, que age em baixas concentrações nas regiões meristemáticas das plantas, promovendo assim, o crescimento e alongamento celular (TAIZ et al., 2017). Plântulas tratadas com BRM32113 e BRM32114 apresentaram aumento no comprimento radicular das plântulas de arroz irrigado da cultivar BRS Catiana em 11,4 e 17\%, respectivamente e na BRS $A 702 \mathrm{CL}, 21,7$ e 30,4\%, respectivamente, em comparação com as sementes não tratadas (controle). Oliveira et al. (2003) e Hungria (2011) relatam que as RPCV proporcionam maior desenvolvimento radicular e isso pode implicar em vários outros efeitos benéficos nas plantas como maior absorção da água e minerais, resultando em plantas mais vigorosas e produtivas, como já observado por Nascente et al. (2017a; 2017b).

As RPCV utilizadas neste estudo, apesar de serem microrganismos coletados em rizosfera de arroz de terras altas, proporcionaram incrementos significativos no comprimento radicular de ambas as cultivares de arroz irrigado. Portanto, a inoculação com os isolados de RPCV mostrou efeito benéfico nos genótipos de arroz, mas, torna-se necessário a realização de outros trabalhos em laboratório, casa de vegetação e campo para investigar as implicações dessas alterações em processos fisiológicos e no desenvolvimento das plantas, bem como na produtividade da cultura.

\section{Conclusões}

Os isolados BRM32110 e BRM32112 se destacaram e promoveram incremento médio de 24,3 e $27,1 \%$, respectivamente, no comprimento de raiz das plântulas de arroz irrigado por inundação, da cultivar BRS Catiana;

Os isolados BRM32109, BRM32110, BRM32111, BRM32112, BRM32113 e BRM32114 proporcionaram incremento médio de $31 \%$ no comprimento radicular das plântulas de arroz irrigado por inundação cultivar A 702 CL.

\section{Referências}

AHEMAD, M.; KIBRET, M. Mechanisms and applications of plant growth promoting rhizobacteria: current perspective. Journal of King Saud University, v.26, n.1, p.1-20, 2014. https://doi.org/10.1016/j.jksus.2013.05.001

BRASIL. Ministério da Agricultura, Pecuária e Abastecimento. Regras para análises de sementes. Brasília: MAPA/ACS, 2009. 399 p.

CONAB. Acompanhamento da safra brasileira de grãos. 2018.

FILIPPI, M. C. C.; SILVA, G. B.; SILVA-LOBO, V. L.; CÔRTES M. V. C. B.; MORAES, A. J. G.; PRABHU, A. $S$. Leaf blast (Magnaporthe oryzae) suppression and growth promotion by rhizobacteria on aerobic rice in Brazil. Biological Control, v.58, n.2, p.160-166, 2011. https://doi.org/10.1016/j.biocontrol.2011.04.016

HUNGRIA, M. Inoculação com Azospirillum brasiliense: inovação em rendimento a baixo custo. 1. ed. Londrina: Embrapa Soja, 2011.

IRRI. Global Rice Science Partnership (GRISP). 2010. $267 p$.

KADO, C. J.; HESKETT, M. G. Selective media for isolation of Agrobacterium, Corynebacterium, Erwinia, Pseudomonas and Xanthomonas. Phytopathology, v.60, n.6, p.969-976. 1970. . https://doi.org/10.1094/Phyto-60-969 
MARTINS, B. E. M. Caracterização morfológica, bioquímica e molecular de isolados bacterianos antagonistas a Magnaporthe oryzae. 2015. $80 \mathrm{f}$. Dissertação (Mestrado em Agronomia) - Escola de Agronomia e Engenharia de Alimentos, Universidade Federal de Goiás, Goiânia-GO, 2015.

MENDES, L. W.; RAAIJMAKERS, J. M.; HOLLANDER, M.; MENDES, R.; TSAI, S. M. Influence of resistance breeding in common bean on rhizosphere microbiome composition and function. The ISME Journal, v.12, n.1, p.212-224, 2017. https://doi.org/10.1038/ismej.2017.158 NASCENTE, A. S.; FILIPPI, M. C. C.; LANNA, A. C.; SOUZA, A. C. A.; LOBO, V. L S.; SILVA, G. B. Biomass, gas exchange, and nutrient contents in upland rice plants affected by application forms of microorganism growth promoters. Environmental Science and Pollution Research, v.24, n.3, p.2956-2965, 2017a. https://doi.org/10.1007/s11356-016-8013-2

NASCENTE, A. S.; FILIPPI, M. C. C.; LANNA, A. C.; SOUSA, T. P.; SOUZA, A. C. A.; LOBO, V. L. S.; SILVA, G. B. Effects of beneficial microorganisms on lowland rice development. Environmental Science and Pollution Research, v.24, n.32, p.25233-25242, https://doi.org/10.1007/s11356-017-0212-y

NAVES, M. M. V.; BASSINELO, P. Z. Importância na nutrição humana. In: SANTOS, A. B.; STONE, L. F.; VIEIRA, N. R. A. A cultura do arroz no Brasil. Santo Antônio de Goiás: Embrapa Arroz e Feijão, 2006. p. 17-30.

OLIVEIRA, A. L.; URQUIAGA, S.; BALDANI, J. I. Processos e mecanismos envolvidos na influência de microrganismos sobre 0 crescimento vegetal. 1. ed. Seropédica: Embrapa Agrobiologia, 2003.

RAJ, S. N.; LAVANYA, S. N.; AMRUTHESH, K. N.; NIRANJANA, S. R.; REDDY, M. S.; SHETTTY, H. S. Histo-chemical changes induced by PGPR during induction of resistance in pearl millet against downy mildew disease. Biological Control, v.60, n.2, p.90-102, 2012. https://doi.org/10.1016/j.biocontrol.2011.10.011

RÊGO, M. C. F.; ILKIU-BORGES, F.; FILIPPI, M. C. C.; GONÇALVES, L. A.; SILVA, G. B. Morphoanatomical and Biochemical Changes in the Roots of Rice Plants Induced by Plant GrowthPromoting Microorganisms. Journal of Botany, v.2014, n.1, p.1-10, 2014. https://doi.org/10.1155/2014/818797

SPERANDIO, E. M.; VALE, H. M. M.; REIS, M. S.; CORTES, M. V. C. B.; LANNA, A. C.; FILIPPI, M. C. C. Evaluation of rhizobacteria in uplant rice in Brazil: growth promotion and interaction of induced defense responses against leaf blast (Magnaporthe oryzae). Acta Physiologiae Plantarum, v.39, n.1, p.258-270, 2017. https://doi.org/10.1007/s11738-017-2547-x

TAIZ, L.; ZEIGER, E.; MOLLER, I. M.; MURPHY, A. Fisiologia e desenvolvimento vegetal. 6. ed. Porto Alegre: Artmed, 2017. 